\title{
ANÁLISIS DEL PAISAJE CULTURAL DE GUADIX Y COMARCA A TRAVES DEL CINE: PROYECCIÓN EDUCATIVA
}

\author{
ANALYSIS OF THE CULTURAL LANDSCAPE OF GUADIX AND \\ REGION THROUGH CINEMA: EDUCATIONAL PROJECTION
}

\section{Manuel CORTÉS-MAGÁN}

\begin{abstract}
Resumen
Guadix y su comarca por la peculiaridad y la belleza de su paisaje cultural ha sido y continua siendo escenario de películas de carácter nacional e internacional, así como escenario de audiovisuales, series y publicidad. En este artículo mostramos un proyecto que tiene como fin analizar la imagen que se ha transmitido de Guadix y su comarca a través del cine. Utilizando para ello, por su valor como documento, diferentes películas rodadas en su territorio. Análisis que nos va a permitir recuperar imágenes de su patrimonio natural, material e inmaterial, a la vez que analizar el carácter estereotipado que en algunas de ellas se ofrece en particular de esta ciudad y su comarca y en general de Andalucía. El producto final será un documental en el que se recogerá el resultado de la investigación.
\end{abstract}

\section{Palabras claves}

Guadix y comarca, paisaje cultural, cine, cultura audiovisual, patrimonio.

\begin{abstract}
Guadix and its region, due to the peculiarity and beauty of its cultural landscape, has been and continues to be the setting for national and international films, as well as the setting for audiovisuals, series and advertising. In this article we show a project that aims to analyze the image that has been transmitted of Guadix and its region through the cinema. Using for this, for its value as a document, different films shot in its territory. Analysis that will allow us to recover images of its natural, tangible and intangible heritage, while analyzing the stereotyped character that some of them offer in particular of this city and its region and in general of Andalusia. The final product will be a documentary in which the result of the investigation will be collected.
\end{abstract}

\section{Key words}

Guadix and region, cultural landscape, cinema, audiovisual culture, heritage.

\section{Manuel CORTÉS-MAGÁN.}

Profesor de Historia, IES Padre Poveda, Guadix, Granada . Correo electrónico: khortes@gmail.com 


\section{ANÁLISIS DEL PAISAJE CULTURAL DE GUADIX Y COMARCA A TRAVÉS DEL CINE: PROYECCIÓN EDUCATIVA}

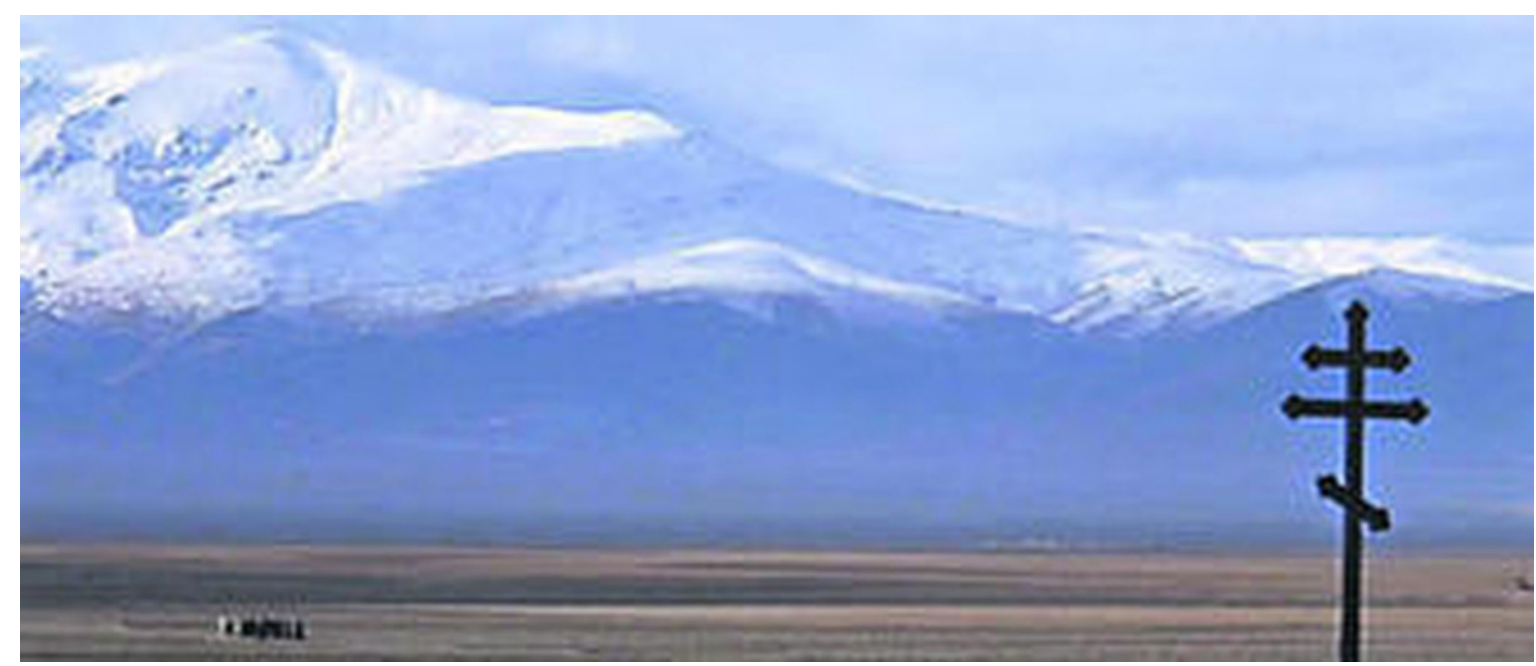

Figura 1. Páramo de la Accitania, con Sierra Nevada. Fotograma de DOCTOR ZHIVAGO. David Lean. (Diciembre 1964) https://youtu.be/q6zNIAXfWoE

\section{INTRODUCCIÓN}

El cine te da la oportunidad de estar en lugares imposibles, donde parece que jamás llegarás a estar en la vida real. Encontrarte de pronto con que esos lugares, que en la pantalla parecían extraños, existen, es más o menos sentir que tus sueños se hacen realidad. $Y$ eso es una sensación fantástica. (Álex de la Iglesia, "800 balas" (2002).

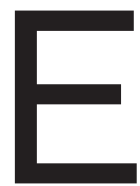

n este artículo presentamos un proyecto de innovación educativa que bajo el título Educar la mirada, está destinado al profesorado en formación de secundaria del Máster en Profesorado de Enseñanza Secundaria Obligatoria y Bachillerato, Formación Profesional y Enseñanzas de Idiomas de la UGR, en el marco de la asignatura Innovación e Investigación en Didáctica de las Ciencias Sociales. Su finalidad es favorecer la competencia investigadora y la alfabetización audiovisual del alumnado con el fin de que valore las posibili- dades educativas del cine y su utilización como documento para el análisis del paisaje cultural de un territorio. Paisaje cultural entendido según el concepto que surge en la Convención del Patrimonio Mundial, adoptada por la Conferencia General de la UNESCO en 1972, en la cual se creó un instrumento internacional único que reconoce y protege el patrimonio natural y cultural de valor universal excepcional. Proporcionando una definición del patrimonio muy innovadora para proteger los paisajes. Pero no será hasta diciembre de 1992 cuando el Comité del Patrimonio Mundial, adopté las revisiones a los criterios culturales de la Guía Operativa para la implementación de la Convención del Patrimonio Mundial, incorporando la categoría de paisajes culturales.

Decisión con la que esta Convención se transformó en el primer instrumento jurídico internacional para identificar, proteger, conservar y legar a las generaciones futuras los paisajes culturales de valor universal excepcional. 
De esta forma el término "paisaje cultural» se irá imponiendo y utilizando en el ámbito científico. La Unesco en el Artículo $1^{\circ}$ de la Convención de año 1972 hacía referencia al paisaje como «las obras combinadas entre el hombre y la naturaleza", clasificándolo como "natural o cultural", quedando excluidos de esta consideración ciertos paisajes. Pero tras la introducción de la Guía Operativa, implantada en la Convención de 1992, se desarrolló la noción de "paisajes culturales" que la UNESCO definió como: el resultado de la interacción en el tiempo de las personas y el medio natural, cuya expresión es un territorio percibido y valorado por sus cualidades culturales, producto de un proceso y soporte de la identidad de una comunidad.

El análisis está centrado en el paisaje cultural de Guadix y su comarca que en este artículo denominaremos también con el nombre romano por el que se conocía el territorio que abarca: Accitania ${ }^{1}$. Elegido por ser un caso paradigmático ya que su paisaje cultural desde las primeras décadas del siglo $\mathrm{XX}$ a la actualidad ha sido el escenario del rodaje de numerosas películas, documentales, cortometrajes, anuncios y series televisivas, que puede consultarse en este enlace: https://drive.google.com/drive/folders/ 105PPcsvVLGJ2J9Ah8Ls27kIKCBJTUa39?us$\mathrm{p}=$ sharing

\section{EL PAISAJE CULTURAL DE GUADIX Y SU COMARCA COMO ESCENARIO DE CINE}

Son muy numerosas y de temática muy diversa las películas que se han rodado en este territorio como queda reflejado en numerosos trabajos (Ventajas y Sánchez, 2003; Carrasco, 2012; Caparros, Fernández y Soler, 1997; Pérez Siquier, 2005). En este artículo no es posible referirse a todas ellas por lo que se hará referencia a lo más significativo.

1. https://es.wikipedia.org/wiki/Comarca_de_Guadix
David Lean recorrió 6.000 km buscando exteriores, siguiendo los bocetos de John Box, quien construía grandes mansiones de hielo con cera. Selecciona la Accitania en Granada, que le ofrecía paisajes y paisanaje. Un lugar adecuado donde crear el ambiente en el que los actores pudieran interpretar, que ofrece el tamaño y la escala adecuada para grandes rodajes. Su trabajo quedó en una de las mejores películas de la historia del cine, Doctor Zhivago (1965), que obtuvo cinco premios Oscar: mejor guion adaptado, dirección artística y decorados, fotografía, vestuario, banda sonora y música.

Muy cercano está el centenario del primer rodaje realizado por estos paisajes, 1924, año en el que se filmaban en Guadix unas escenas de una producción española dirigida por Maximiliano Thous, La alegría del batallón.
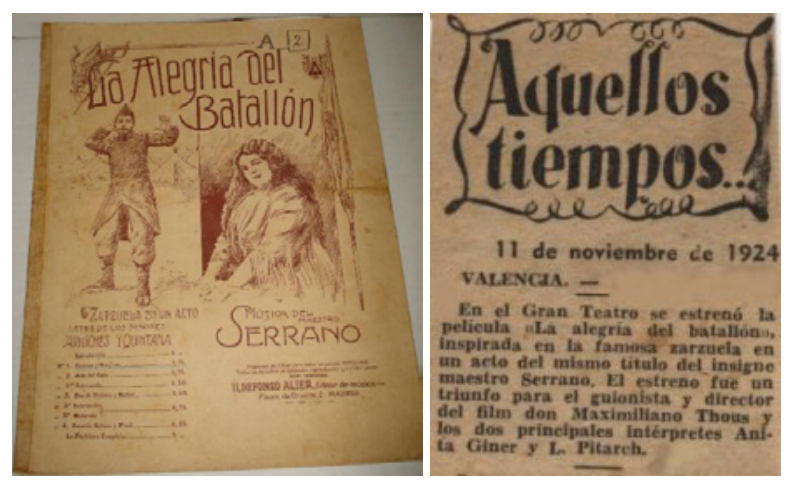

Figura 2 a y $b$. Programa de la primera película rodada en la Accitania. "LA ALEGRIA DEL BATALLÓN" (1924) Dirigida por Maximiliano Thous, con Pepita Bastida, José Baviera, José Benítez, (https://www.filmaffinity.com/es/ film537507.html)

Hasta hoy han pasado muchos directores, actores, algunos los mejores y más conocidos mundialmente, otros mejor no recordarles. En cualquier otro lugar con un solo rodaje que tuviera su escenario sus paisajes, puede promocionarlo y difundir con orgullo sin par. Imaginar cuanto se podría hacer para poner en valor este Patrimonio 


\section{ANÁLISIS DEL PAISAJE CULTURAL DE GUADIX Y COMARCA A TRAVÉS DEL CINE Manuel CORTÉS-MAGÁN}

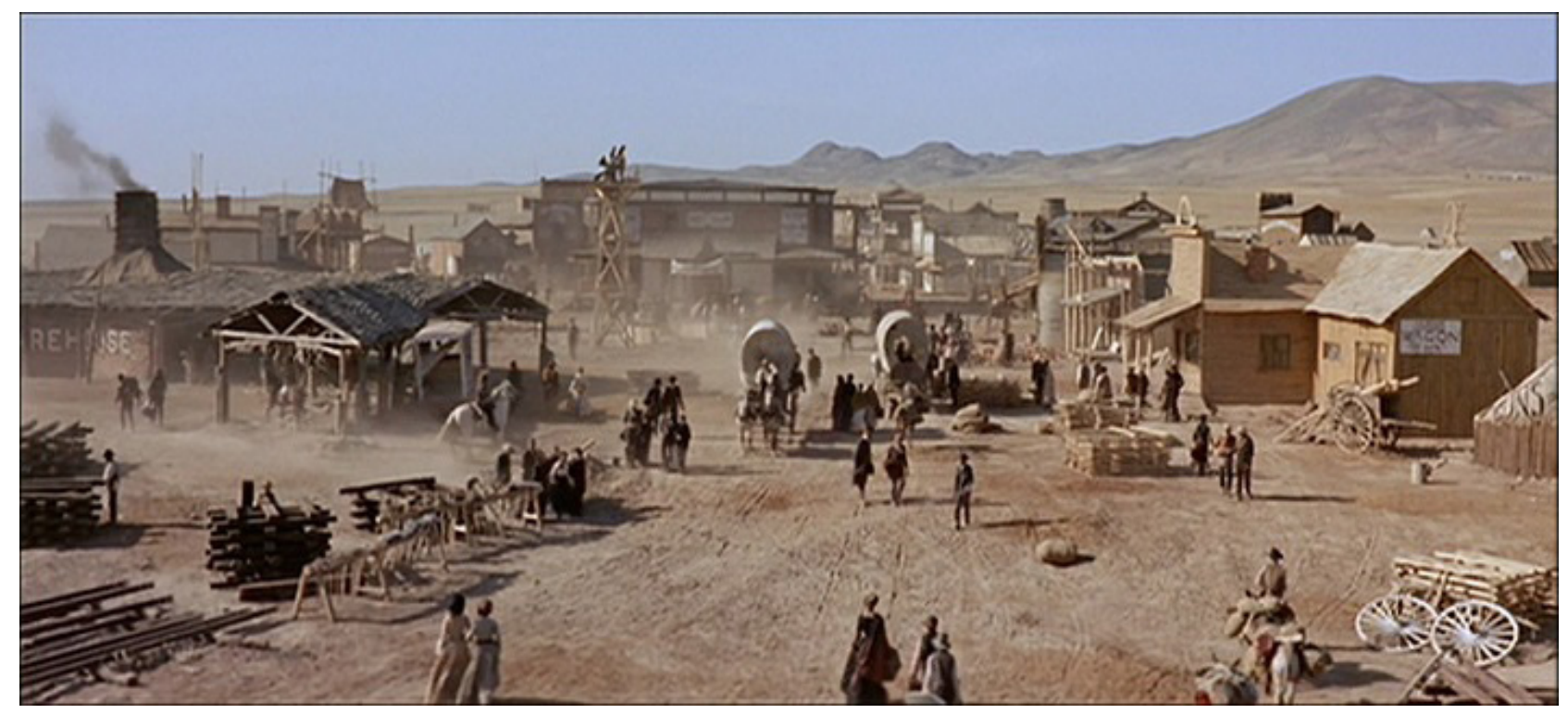

Figura 3. Poblado Leone en La Calahorra, Accitania. www.cinematographe.it

Cinematográfico. Pues en la Accitania, se han superado los más de setenta largometrajes, a lo que hay que sumar un buen número de cortometrajes, documentales, capítulos de series, spots publicitarios, videoclips musicales,... Todos ellos han hecho posible difundir su paisaje cultural en las pantallas de cine y televisión por todo el planeta.

Hasta los años 50, los rodajes fueron testimoniales, escasos y esporádicos. El primero y curioso es el caso de Morena Clara (1936). Dirigida por Florián Rey con Imperio Argentina y Miguel Ligero, que fue proyectada en plena guerra y fue muy taquillera en las "dos zonas en conflicto".

Ya cercanos los años 60, se ponen en rodaje seis producciones, tres británicas, una italiana, una coproducida con una española y otra más solo española. Se ha de esperar al año 64 , pero merece la pena tal espera. Llega a la Accitania David Lean para dirigir la película Doctor Zhivago, (1965), protagonizada por Omar Sharif, Julie Christie, Geraldine Chaplin y Alec Guinness. El testigo lo recoge y lo trabaja intensamente, Sergio Leone, tanto y tan bien que rueda la Trilogía del Dólar, compuesta por las películas tituladas: Por un puñado de dólares (Per un pugno di doIlari, 1964); La muerte tenía un precio (Per qualche dollaro in più, 1965) y El bueno, el feo $y$ el malo (II buono, il brutto, il cattivo, 1966). Para ello precisa y lo hace, se construye su propio pueblo, en la Calahorra-Dólar: Fragstone.

Se sirve del ferrocarril y sus líneas cercanas a Guadix: Alquife, Huéneja, Dólar, Hernán Valle y Estación de Guadix, con una joya del vapor, $\mathrm{La}$ Guadix locomotora de vapor construida en Bilbao en 1928 en los talleres Babcock \& Wilcox, que algunos adjudican a otro fabricante, denominándola de forma errónea Baldwin. Un paisaje esplendido en el que se fijan miles de ojos, para convertirlo en parte de su plató, válido para cualquier época, no siendo el mar, resulta adecuado desde el páramo, a sus cuevas, badlands (hoy reconocido Geoparque Mundial por la Unesco en Granada), edificios históricos, con castillo, catedral, plazas,...etc.. 


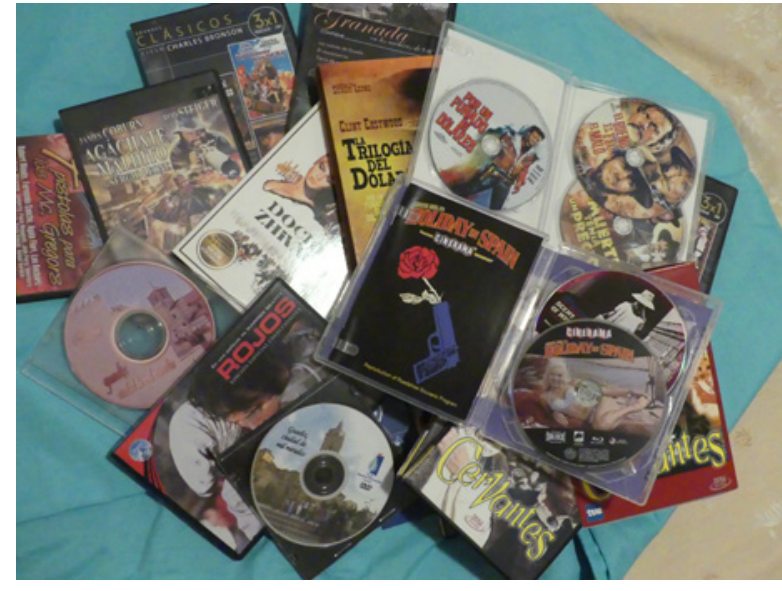

Figura 4. Rodajes en la Accitania, desde grandes producciones a modestos rodajes, incluso alumnos de un IES de Guadix, premiados con el Premio Nacional de Periodismo "Ciudad de Guadix" "Pedro Antonio de Alarcón". Con "Guadix, ciudad de mil miradas". Foto: Khortés Magán.

La Accitania florece como escenario de cine y en 1960 se rodará en ella una película innovadora: Holliday in Spain dirigida por J. Cardifff al aplicarse en su rodaje técnicas muy novedosas para la época como la elaboración de un guión pensado para la exhibición en sala mediante el uso del sistema Odascope (Smell-O-Vision), que hacía posible la liberación de aromas asociados a determinados fragmentos y pasajes del film. Un recurso que décadas después se ha vuelto explorar en los cines más vanguardistas que en una vuelta a lo ya explorado hace tiempo, lo denominan experiencias 360. Será un periodo en el que fijarán su mirada en esta tierra un francés para crear cine de terror, un inglés el suspense y un estadounidense el western. Este género cinematográfico será el que abra las puertas del cine popularizado, donde se magnifica al héroe americano, el paisaje y sobre todo el tren. Fórmula que sigue funcionando desde 1903, cuando Edwin S. Porter creó The Great Train Robbery (Asalto y robo de un tren). Hacer referencia a todas ellas excede los límites de este texto. Pero como ejemplo bas- te citar su variada temática: spaghetti western, western europeo o eurowestern, y de temática medieval, terror, cómicas o carreras de coches, motos,... una de las cuales tuvo como protagonista al miembro de los Beatles, Ringo Starr, El justiciero ciego, (Blindman), película dirigida por Ferdinando Bal o El ídolo, dirigida por Michael Apted con David Essex, Adam Faith, Larry Hagman,... Rodada en el castillo de La Calahorra. No podemos dejar de ampliar la referencia a una de las más espectaculares rodadas en Guadix, anteriormente citada, Scent of Mystery película dirigida por Jack Cardiff con Denholm Elliott, Peter Lorre, Beverly Bentley, Paul Lukas(1960). Y una comercial y muy conocida Indiana Jones y la última cruzada, dirigida por Steven Spielberg con Harrison Ford, Sean Connery, Alison Doody, Denholm Elliott (1989) y un amplio número.

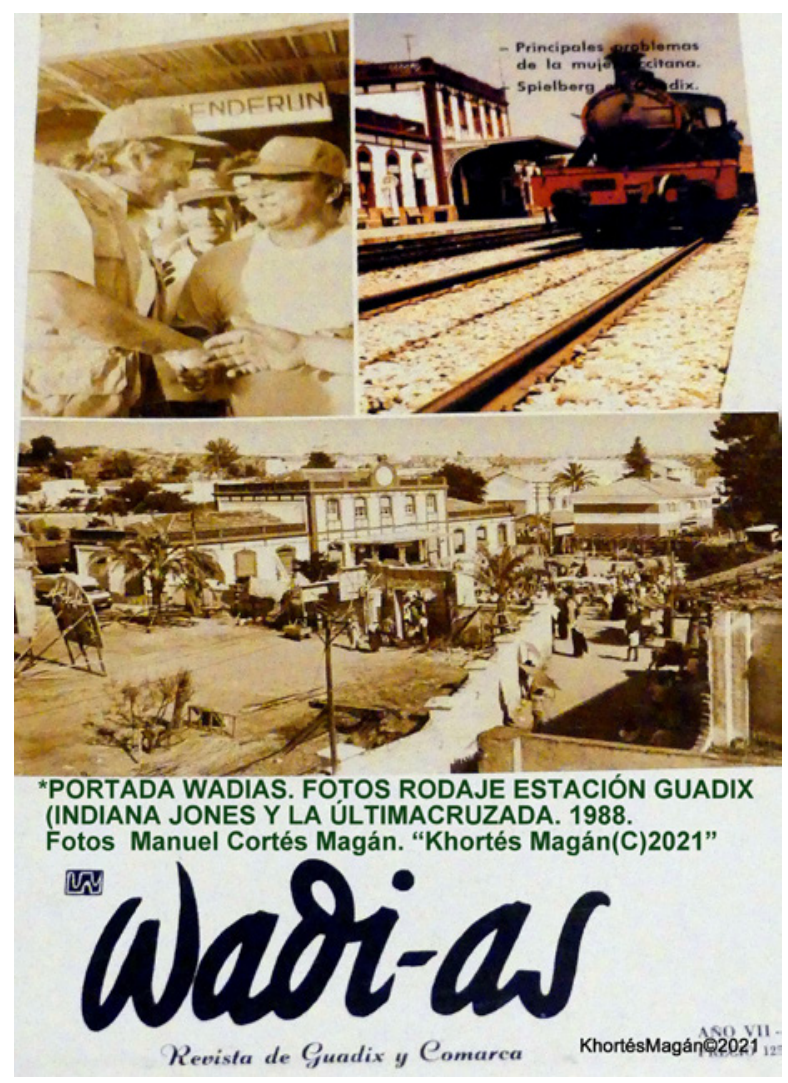

Figura 6. Fotos del rodaje en la Estación de Guadix (Indiana Jones y la última cruzada) KhortésMagán(C2021 https://youtu.be/jkK96Oop-3w 


\section{ANÂLISIS DEL PAISAJE CULTURAL DE GUADIX Y COMARCA A TRAVÉS DEL CINE Manuel CORTÉS-MAGÁN}

Pero no solo el paisaje cultural de la Accitania será escenario de grandes producciones, entendemos preciso, señalar su incorporación a series televisivas centradas en personajes históricos, con Isabel (Banalocha et al., 2012-2014) LACE I y LACE II (1983-1984) Miniserie de televisión estadounidense de Lorimar Productions, emitida por ABC, con gran éxito de público.

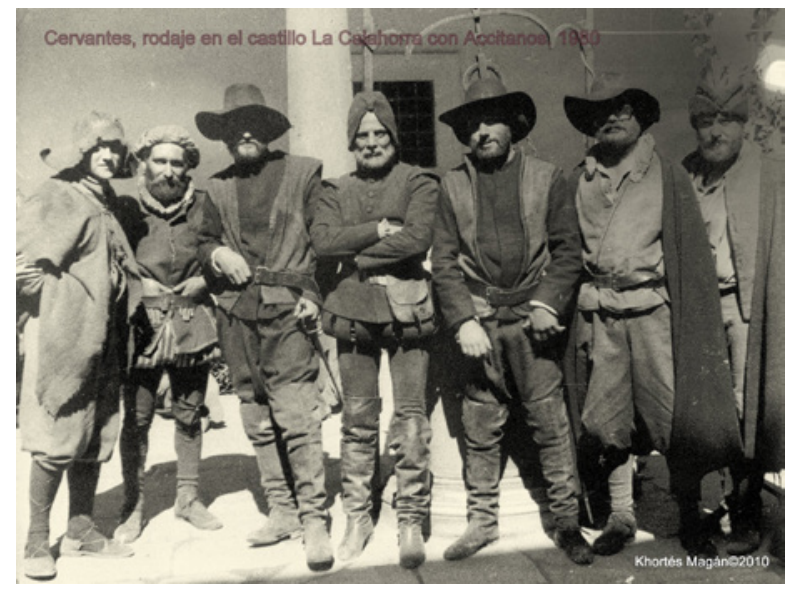

Figura 5. Rodaje de Cervantes en el castillo de La Calahorra, con figuración de la zona y el protagonista de la misma, Julián Mateos, cuestión que ha sido apreciada por las productoras, puesto que supone disponer del "paisanaje» conocedor de los rodajes cinematográficos. CERVANTES 1981. Dirigido por: Alfonso Ungría, Con Paco Rabal, Julián Mateos. Carlos Lucena, Carmen Maura, Manuel Alexandre,...

También TVE realizaba Cervantes (1981). Y se mantiene actualmente con otra, rodada recientemente en el mismo castillo de La Calahorra, Inés del alma mía ( 2020), miniserie de TV, dirigida por Nicolás Acuña, Alejandro Bazzano con Elena Rivera, Eduardo Noriega, Benjamín Vicuña, Enrique Arce. Producciones documentadas, basadas en la ficción que ayude a construir y fusione el relato, al lenguaje cinematográfico, brindando al alumnado un adecuado y motivador aprovechamiento didáctico. Si se desprecia ese potencial, el que generan los medios y la industria audiovisual contemporánea, ... «la comu- nidad docente e investigadora estaría mirando hacia otro lado y permitiendo que una narrativa hegemónica, la mediática y digital, construya la propia realidad" (Marfil-Carmona, 2018, p. 277).

\section{EL VALOR EDUCATIVO DE LOS AUDIOVISUALES: EL CINE}

Debemos utilizar el cine ya que como parte del patrimonio cultural, constituye un legado cuya aportación es sustancial para la construcción del "capital simbólico de una sociedad", y sobre todo en una zona deprimida socialmente, precisa potencial la vertiente del patrimonio que recuerdan Cambil y Fernández (2017, p. 31) en su recorrido por las bases conceptuales del concepto de patrimonio cultural y, en concreto, en esa referencia a la memoria, la identidad y el valor sentimental del mismo (Moreno, 1999).

Razonablemente se ha de tener presente que, junto a la representación del patrimonio natural, material e inmaterial en el cine, sea cual sea su grado de ficción, estas obras son, en sí mismas, un legado también patrimonial, cuyo conocimiento y análisis resulta de gran interés para su aplicación en cualquier contexto docente de la educación formal y no formal. Brindándonos una gran oportunidad, para forjar "aulas sin cuatro paredes" y acercar a las mismas su riqueza paisajista y patrimonial.

En la actualidad es impensable negar el valor educativo del cine cuya presencia es una realidad en las diferentes etapas educativas. Su utilización como recurso debe partir de educar la mirada, pero también, su objetivo debe ser favorecer la reflexión y el espíritu crítico del alumnado que se haga preguntas sobre lo que las imágenes trasmiten y cómo lo hacen. Han de conocer el contexto social y cultural del momento y los valores identitarios y patrimoniales que la películas contienen. Sin olvidar que vivimos en un mundo "globalizado", en el que internet nos amplia en modo significativo, "la alfabetización audio- 
visual", cada día más presente en los currículos de las diferentes etapas educativas. Tenemos unas aulas cada día más repletas de "alumnos digitalizados". Fijemos el objetivo en capacitarles para que comprendan y analicen la cultura audiovisual de la sociedad en la que vive y, los medios de producción utilizados para generarla, favoreciendo que sean lectores críticos y creativos. Un mundo en el que Internet nos permite recuperar en cualquier momento los rodajes y películas precisadas. Hacerlo en grupo, trabajar juntos los hace integrarse y favorece la integración. Va quedando lejano ver una película en una sala de cine, cuestión que no se ha de perder, para ello el trabajo final, será siempre el visionado del trabajo en una sala o en el salón de actos del centro donde se implemente el proyecto.

Acogemos el reto que nos plantea la Sociedad de la Información y el Conocimiento, fundamentándolo en los siguientes aspectos: aprender a aprender, viendo, analizando y formándose en las técnicas audiovisuales en el lenguaje filmico, para elaborar su propia producción audiovisual. Vamos dirigidos a la producción o creación de imágenes o de videos ya que en la actualidad los jóvenes están inmersos en la cultura de la autoproducción. Las webcam y redes sociales, los dispositivos móviles han contribuido a que la grabación de imágenes sea una actividad cotidiana, por lo que es urgente formales es su uso adecuado y respetuoso en sus relaciones sociales, aprendizaje más ordenado y especialmente a reflexionar sobre la función que tiene la imagen, pero también el sonido, la luz, el color, que integre con otros temas transversales como, la ética, el derecho de imagen, la propiedad intelectual, la protección de datos, etc.

Entorno digital que invita a una alfabetización audiovisual de los jóvenes que debemos aprovechar para crear un entorno de imágenes que sin duda favorece la educación en cine.
Por lo tanto, en la profundización y búsqueda de esos clichés y de su origen en la creación cultural, el cine es una herramienta de gran utilidad en cualquier contexto investigador o didáctico, como puede ser el caso de la enseñanza de historia, de la geografía, el Arte y Patrimonio, al permitir visualizar los rasgos que se asocian a una época o a un país a través de la mirada creadora, la selección de lugar, personajes, escenarios $y$, en definitiva, todo lo que tiene que ver con la articulación narrativa y discursiva de la obra fílmica, en la línea de los trabajos de cultura visual (Hernández, 2007; Mirzoeff, 2016; Walker y Chaplin, 2002).

\section{ANÁLISIS DEL PASAJE CULTURAL DE GUADIX Y SU COMARCA A TRAVÉS DEL CINE}

La base sobre la que se realizará el análisis es la narrativa audiovisual (Bordwell, 1996; Canet y Prósper Ribes, 2009; Gómez Tarín, 2011), aunque también se tiene en cuenta el análisis del significado (Carmona, 2003; Zunzunegui,1998) o de la realización cinematográfica (Schmidt Noguera, 2008). Podría sumarse, además, entre otras metodologías, la perspectiva de género (Mulvey, 1988). Teniendo en cuenta estas bases conceptuales, para llevar a cabo el análisis se han seleccionado diferentes categorias y criterios que van desde lo temático hasta una profundización textual y narrativa, finalizando en una reflexión en torno al modelo de sociedad que se representa en las películas, por extensión, otras de la época que podrían sumarse en el futuro.

\section{OBJETIVOS}

El objetivo general de la propuesta recogida en este texto es llevar a cabo una experiencia inicial de análisis con el profesorado de secundaria en formación del Máster en Profesorado de Enseñanza Secundaria Obligatoria y Bachillerato, 


\section{ANÁLISIS DEL PAISAJE CULTURAL DE GUADIX Y COMARCA A TRAVÉS DEL CINE Manuel CORTÉS-MAGÁN}

Formación Profesional y Enseñanzas de Idiomas de la UGR de las películas seleccionadas de acuerdo a los objetivos del proyecto, rodadas en la Accitania, por su valor como arte de la memoria individual y colectiva. Experiencia que puede extrapolarse a otros contextos y lugares.

Dicho objetivo general se concreta en los siguientes objetivos específicos:

- Identificar las claves narrativas en la generación de estereotipos y sintetizarlos desde el punto de vista de la influencia social y la generación de un modelo de país visto desde el exterior.

- Valorar los aspectos estéticos, discursivos, formales y técnicos a la hora de la representación de esos contenidos, con una atención especial a la innovación tecnológica en el cine de la época.

- Trabajar de modo interdisciplinar y desarrollando «Aprender a aprender».

- Generar un modelo de aproximación crítica y pedagógica al cine desde la perspectiva de la Didáctica de las Ciencias Sociales.

\section{METODOLOGÍA}

El análisis se llevará a cabo con una metodología cualitativa centrada en la aplicación del paradigma de análisis de contenido (Bardin, 1986; Krippendorff, 1990). Sistema de trabajo que secuencia y ordena la reflexión crítica, ya sea atendiendo a los aspectos de carácter estético y formal en el análisis de la imagen (Aparici y García Matilla, 2008) o, siguiendo la tradicional diferenciación entre historia y discurso en análisis fílmico (Chatman, 1990). Centrando el estudio en los elementos diegéticos que conforman la historia: personajes, acciones, lugares representados y tratamiento de la estrategia temporal (García y Rajas, 2011; García Jiménez, 1993; Prósper Ribes, 2004), además de determinadas cuestiones técnicas y discursivas de interés, que se tiene en cuenta en el propio guión cinematográfico y debe ser considerado en el texto audiovisual analizado.

\section{Diseño de la propuesta}

\section{Contexto y participantes}

El proyecto se implementará en el marco de la asignatura Investigación e Innovación en Didáctica de las Ciencias Sociales que se imparte en el Máster en Profesorado de Enseñanza Secundaria Obligatoria y Bachillerato, Formación Profesional y Enseñanzas de Idiomas de la UGR, y contará con la participación de dos profesores del Departamento de Didáctica de las Ciencias Sociales y la colaboración de un profesor de Educación Secundaria. El número de participantes será de cien alumnos/as.

Para el desarrollo del proyecto se seleccionarán cuatro películas de distinta temática rodadas en la Accitania a través de las cuales, el alumnado organizado en grupos y mediante una metodología participativa y colaborativa se llevará a cabo un análisis del paisaje cultural de ese territorio de acuerdo a las categorías establecidas.

De acuerdo con los objetivos mencionados el proyecto tiene una doble finalidad: de un lado aprender a ver y a descubrir lo que se dice, cómo se dice y por qué se presenta al espectador de una manera determinada y en segundo, conocer el proceso creativo de los productos audiovisuales, utilizando su propio patrimonio cercano. Facilitando que el alumnado adquiera las competencias necesarias para entender de forma crítica el universo cultural audiovisual, capacitándolo para enseñar, leer e interpretar este lenguaje y la realidad que nos muestran los medios audiovisuales, en nuestro caso el cine. Teniendo en cuenta que la educación en la imagen ya sea fija o en movimiento, debe ir más allá del 
conocimiento de la técnica del lenguaje audiovisual y de sus recursos expresivos. "Aprender a aprender». Hacerles protagonistas, investiga- ción de su patrimonio cinematográfico, la lluvia de ideas, elaboración de guiones, visitas de los escenarios, rodajes y montaje.

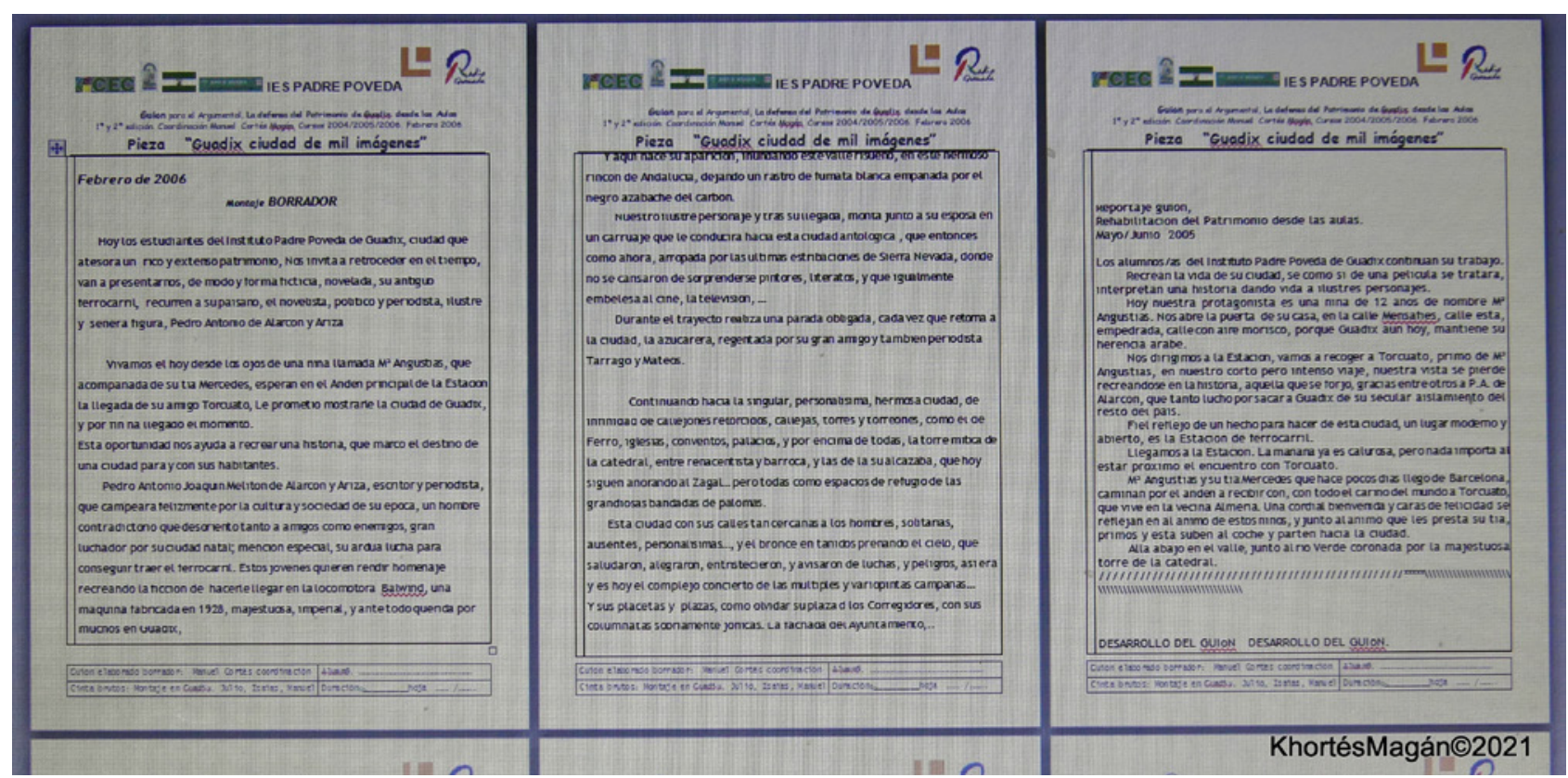

Figura 7. Ejemplo de guión. Guion elaborado alumnado y profesor, para el Argumental "Guadix, ciudad de mil miradas" IES Padre Poveda. Premiado con el premio nacional de periodismo "Ciudad de Guadix, Pedro Antonio de Alarcón".

\begin{tabular}{|l|l|}
\hline \multicolumn{2}{|c|}{ Fases del proyecto } \\
\hline Fase diagnostica & Se realizará mediante una DAFO \\
\hline Fase de implementación & $\begin{array}{l}\text { Organización del trabajo en grupos } \\
\text { Selección de las películas } \\
\text { Establecimiento del análisis en función de las categorías } \\
\text { Análisis de los datos obtenidos }\end{array}$ \\
\hline Fase de evaluación & Evaluación de los resultados del análisis en función de las categorías \\
\hline & Análisis y evolución de los resultado \\
\hline Conclusión y difusión & Elaboración de conclusiones y de un video con las imágenes seleccionada \\
\hline
\end{tabular}




\section{ANÁLISIS DEL PAISAJE CULTURAL DE GUADIX Y COMARCA A TRAVÉS DEL CINE Manuel CORTÉS-MAGÁN}

\section{ANÁLISIS DEL CONTENIDO}

Siguiendo las bases metodológicas del análisis fílmico (Aumont y Marie, 1990; Cassetti y Di Chio, 1991), pero adaptando la estructura del estudio a su objetivo principal, las categorías que se han tenido presentes son las siguientes, progresando desde la esencia del contenido y el análisis textual hasta la valoración contextual e histórica:

- Temática, tópicos y trama -análisis de guion (Escalonilla, etc.).

- Análisis técnico, formal y discursivo.

- Análisis de la historia: personajes, acciones, espacio y tiempo.

- Valoración del contexto social.

A lo que se unen: observar, recoger y anunciar unas bases metodológicas para el análisis de imágenes, que estén estrechamente relacionadas con las concepciones epistemológicas que el alumnado adopta para llevar a cabo su trabajo. A continuación, se pueden poner en común, y leer cómo han sido aplicadas en un trabajo que estudia los paisajes y el patrimonio.

La relación establecida entre las bases metodológicas y el documento a analizar es aquello que se pretende evidenciar, comentando el porqué de las decisiones tomadas durante el trabajo de análisis y estableciendo un diálogo con aquello que las fuentes artísticas aportan al análisis y articulación del discurso histórico. (Gómez y Casanovas, 2017).

El aspecto técnico, formal y discursivo permite que la mirada analítica se dirija al uso del lenguaje fílmico, y estudiar cómo adaptar un texto escrito al lenguaje cinematográfico. Junto a los planos que se corresponden a una planificación clásica en Hollywood, uno de los rasgos dis- cursivos más interesantes es las innovaciones aportadas por algunos de los directores y que queda plasmada en su película.

Sólo un recorrido por el papel de las mujeres en las películas rodadas en la Accitania, permite comprender y realizar un estudio de la representación distorsionada de la realidad desde una perspectiva machista.

Respecto al paisanaje, merece la pena prestar especial atención a los contextos de actividad humana. El interés de esa múltiple y coral presencia de personajes está en analizarlos como un inventario de connotaciones que nos permiten hacer una diagnóstico de esa visión de nuestro patrimonio visto desde el exterior. Como sucede también con las otras tipologías de escenarios, muchos de ellos tienen tanta fuerza que puede competir con los actores. Queda claro, en cualquier caso, que el debate sobre la representación de la realidad, claramente deformante y estereotipada pero, a la vez, respetuosa a su manera y fiel con algunos escenarios y costumbres, se convierte en una oportunidad para la enseñanza de la historia, del patrimonio cultural y del propio lenguaje cinematográfico favoreciendo con ello la identidad y la memoria.

\section{VINCULACIÓN DE LOS OBJETIVOS CON EL CONTEXTO}

Vinculada al objetivo principal de este estudio, es la combinación del paisaje de la Accitania, con las ideas concebidas por las mentes más preclaras del cine, que han rodado algunas obras geniales cine. Un territorio en una obra fílmica arropada por la fotografía y la música, no podemos olvidar al recientemente fallecido Ennio Morricone (Roma, 10 de noviembre de 1928-ib., 6 de julio de 2020). Por ello, es importante impulsar el visionado crítico que unido a la contextualización de la época, fomente la comprensión del legado patrimonial y de la historia, pero también la capacidad para disfru- 
tar y encontrar sentido a los recursos propios del lenguaje audiovisual y cinematográfico, integrando la Didáctica de las Ciencias Sociales con la Educación Patrimonial y Mediática. En concreto, se ha podido comprobar cómo el diseño de personajes, acciones y lugares confirma esos prototipos sociales que, en España, fueron firmemente construidos y consolidados, especialmente a través del cine y de la representación del turismo.

Con casi más de cien años de historias contadas a través del cine, hemos tenido la oportunidad de reír y llorar, de recordar e incluso anhelar una época. Es cuando estamos ante la pantalla que podemos revivir un sentimiento, e incluso descubrir nuevas sensaciones al ver el mismo filme en distintos momentos de nuestra vida. Las localizaciones, el vestuario y los paisajes nos llevan a escenarios imposibles; a lugares que sólo con la magia del cine podemos conocer.

Pero no sólo la imagen nos ha cautivado, aun siendo las más poderosas del territorio, que provienen principalmente de su llamativo paisaje natural, nace de hecho la palabra en imágenes. Crear sueños que captaron la realidad, adaptaron novelas para hacerlas real como Emerald City (2017), Serie de TV, dirigida por Matthew Arnold (Creador), Josh Friedman (Creador) Y Tarsem Singh con Adria Arjona, Oliver Jackson-Cohen, Ana Ularu, Gerran Howell,... rodada en las cuevas de Guadix y el castillo de La Calahorra.

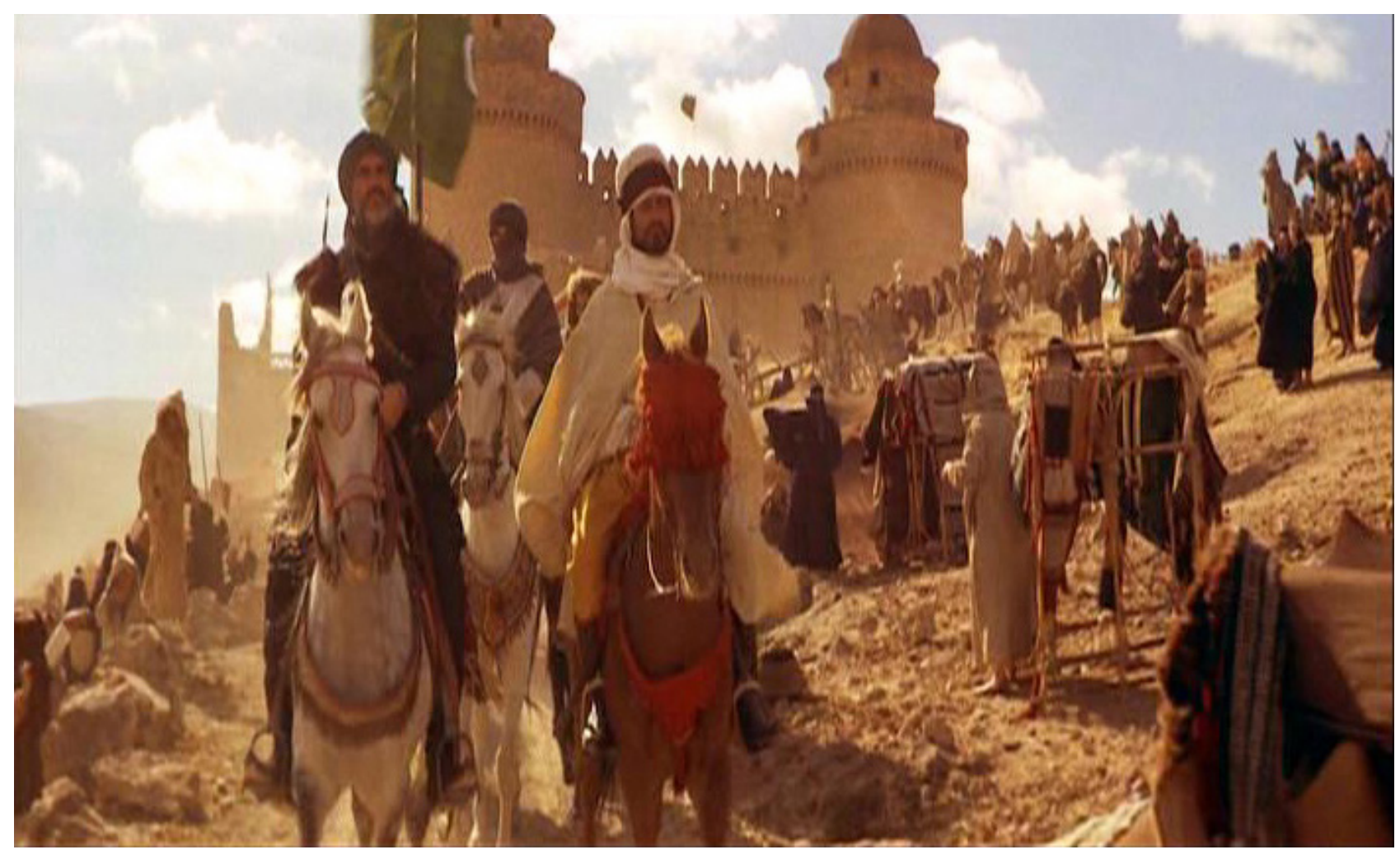

Figura 8. Castillo de La Calahorra. Accitana. El viento y el león es una película dirigida por John Milius con Sean Connery, 1975. 


\section{ANÁLISIS DEL PAISAJE CULTURAL DE GUADIX Y COMARCA A TRAVÉS DEL CINE Manuel CORTÉS-MAGÁN}

El interés por el turismo cinematográfico y la búsqueda de localizaciones de rodaje no ha hecho más que crecer exponencialmente. $Y$ esa fijación atrapa por igual tanto a aficionados como a estudiosos de la materia, bien sea por los atractivos escenarios naturales utilizados o porque siempre el cine es eminentemente popular, para todos los públicos, por eso es preciso poner en valor el paisaje y lugares de la Accitania. Puede focalizar el interés de fans venidos desde muy distintos puntos del globo, dispuestos a pasar largas horas, incluso pernoctar para descubrir la vía, el puente, el rincón en la ciudad, como del páramo,... muchos de ellos ocultos tras décadas de crecimiento incontrolado de la vegetación, y el irresponsable abandono de lugares inmortalizados por los rodajes. La mitomanía derivada de la pasión por el cine, concretamente, por ciertas escenas y localizaciones grabadas a fuego en la retina de los espectadores, conjuga una provechosa manera de elegir los destinos vacacionales que une contacto con la naturaleza, senderismo y cultura a partes iguales.

¿Cómo si no se puede explicar que los pioneros en la "caza" de localizaciones wéstern españolas, el japonés Yoshi Yasuda, o el americano Hervé Attia, descubrieran muchos lugares de rodaje ignotos para los espectadores autóctonos?

En resumen hay que referirse al patrimonio filmico y por tanto arte de la memoria y la identidad. Testimonio del contraste entre una sociedad que comenzaba a desarrollarse tras un periodo difícil de posguerra en España y Europa. Muchísimo menos en un entorno rural y sin industrializar, incluso las Minas de Alquife, servían a intereses ingleses y franceses, quedando el esfuerzo duro a los mineros, mucho fue lo que extrajeron de esta tierra a cambio de tan poco, salvo el ferrocarril que precisaban para llevar el mineral a los altos hornos lejanos. Sin embargo el cine ofrece todo lo contrario, promoción y turismo.
También y como recomendaciones para la acción educativa con materiales audiovisuales que, a su vez, son patrimonio fílmico, este trabajo se integra en un modelo de aproximación y pedagógica interdisciplinar, siendo recomendable el estímulo del análisis crítico basado en el descubrimiento del potencial de aprendizaje que constituye el estudio del S. XX y afortunadamente continua en el presente siglo. Ejemplo de ello una acción recomendada es identificar rasgos estéticos y discursivos, como el destacado color y el predominio del plano en contrapicado o el travelling en una road movie. Además, junto a la comprensión del lenguaje audiovisual puede estimularse la propia acción creativa, basada en la creación de un rodaje, montaje y exhibición del mismo.

Por último, junto al debate cinematográfico es importante estimular, de forma diferenciada, una reflexión sobre esa época y la realidad que muestran los rodajes de tan gran diversidad temática de películas que abarca desde la crítica política como la gran y reconocida Rojos, Reds dirigida por Warren Beatty con Warren Beatty, Diane Keaton, Jack Nicholson, Edward Herrmann ....(1981); la temática social como Yo soy la revolución película dirigida por Damiano Damiani con Gian Maria Volonté, Klaus Kinski, Martine Beswick, Lou Castel(1966); religiosas como Poveda dirigida por Pablo Moreno con Raúl Escudero, Elena Furiase, Silvia García, Miguel Berlanga .... (2016). Incluso la descarnada critica al empresario ruin hasta la muerte que podemos ver en: Hasta que llegó su hora, dirigida por Sergio Leone con Henry Fonda, Charles Bronson, Claudia Cardinale, Gabriele Ferzetti.

Una mención especial merece Sergio Leone y el spaghetti western, director al que debemos la popularización de los escenarios de la Accitania, idóneos para el eurowestern desde que ubicara el comienzo de La muerte tenía un precio (Per 


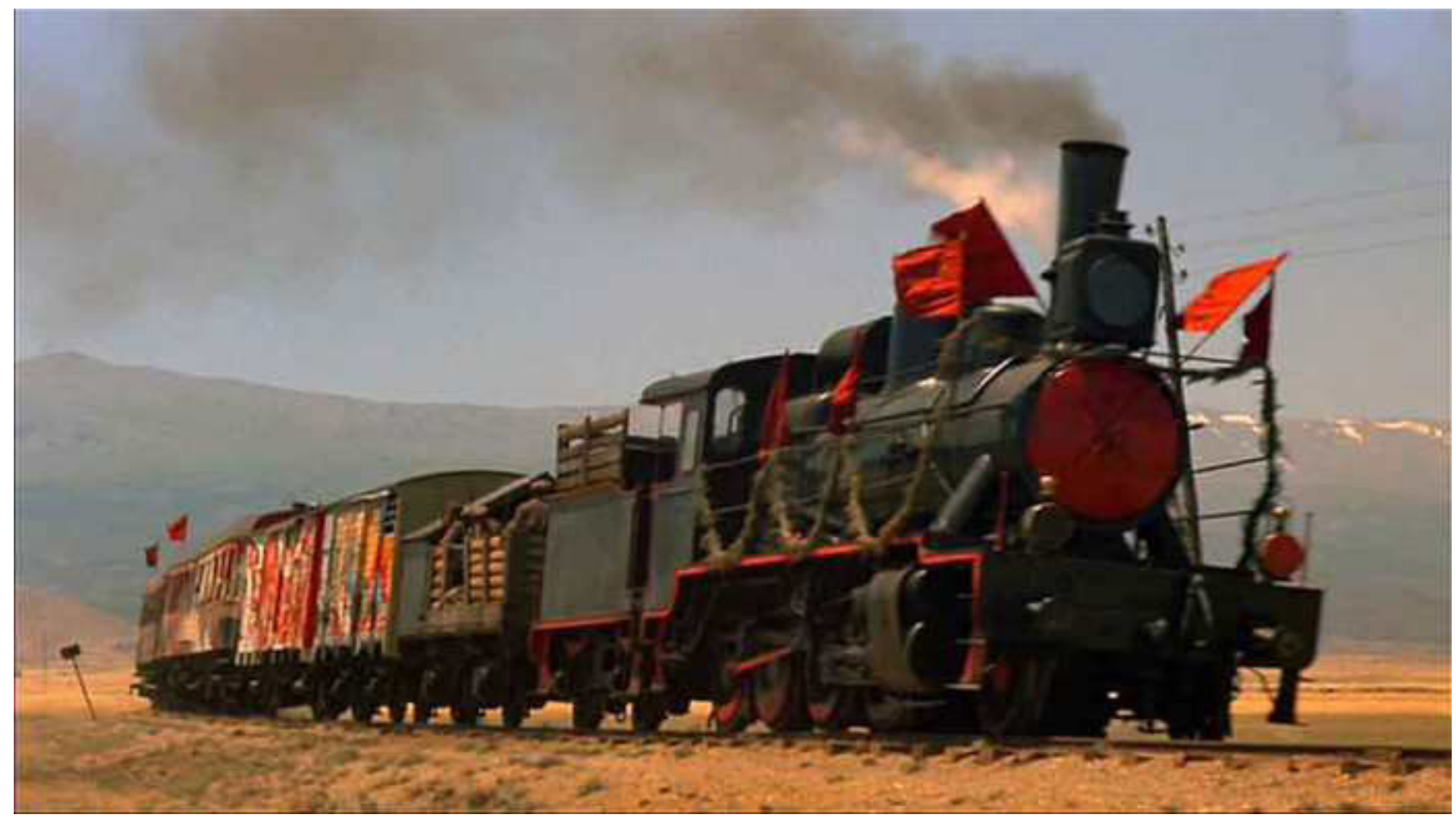

Figura 9. Fotograma de la película Reds" (1981) dirigida por Warren Beatty con Warren Beatty, Diane Keaton, Jack Nicholson. En el se ve La GUADIX, Locomotora de vapor a través del páramo y al fondo Sierra Nevada. https://youtu.be/GbqFoGSzxYo

qualche dollaro in più, 1965) en un árido páramo, a mil metros de altitud, del municipio de La Calahorra, enclavados estratégicamente a las faldas de Sulayr, norte de Sierra Nevada y la sierra de Gor y el Valle del Zalabí. Recordamos a Lee Van Cleef deteniendo el tren y saliendo de un vagón con su caballo, y el castillo de La Calahorra que se "cuela" en plano. Genial igualmente Leone cuando hace hablar al silencio, con los larguísimos minutos de la llegada del tren, con los pistoleros esperando con solo tres caballos, mientras marca el ritmo un añado molino de viento. Curiosamente Al Mulock rodaría sus últimas secuencias, antes de intentar suicidarse, tirándose desde la ventana de un hotel en la ciudad de Guadix, por esa época en estos lares, pocos vicios de ese tipo se podían satisfacer. Acabo falleciendo por la tortuosa carretera hasta un hospital en Granada, los maledicentes re- fieren que Leone precisó quitarle las ropas para continuar el rodaje.

El diseño de los edificios de la ciudad de Flagstone corrió a cargo de Carlo Leva con la ayuda de Carlo Simi, habituales colaboradores en los decorados de la anterior "trilogía del dólar" de Sergio Leone. Tan solo unas penosas ruinas del poblado se mantienen a día de hoy en este mítico enclave cinematográfico de La Calahorra, muy frecuentado no obstante por los amantes del eurowestern, al igual que ocurre con la contigua y anteriormente mencionada estación de tren real del municipio. Los escenarios construidos por Leone fueron utilizados en el rodaje de otras películas concretamente en la estación de la Calahorra y en "Tucumcari» que la construye a unos dos kilómetros, en la vía a Los Pozos de Alquife, que en realidad era una casilla del 


\section{ANÁLISIS DEL PAISAJE CULTURAL DE GUADIX Y COMARCA A TRAVÉS DEL CINE Manuel CORTÉS-MAGÁN}

guardabarreras para custodiar un paso a nivel cercano, engalanada para cada ocasión con sus adecuados decorados será el lugar donde se rodarán emulando a Leone películas de distintos géneros y temática (Simi, 1998; Prats y Mayol, 2001; Gaberscek, 2007).

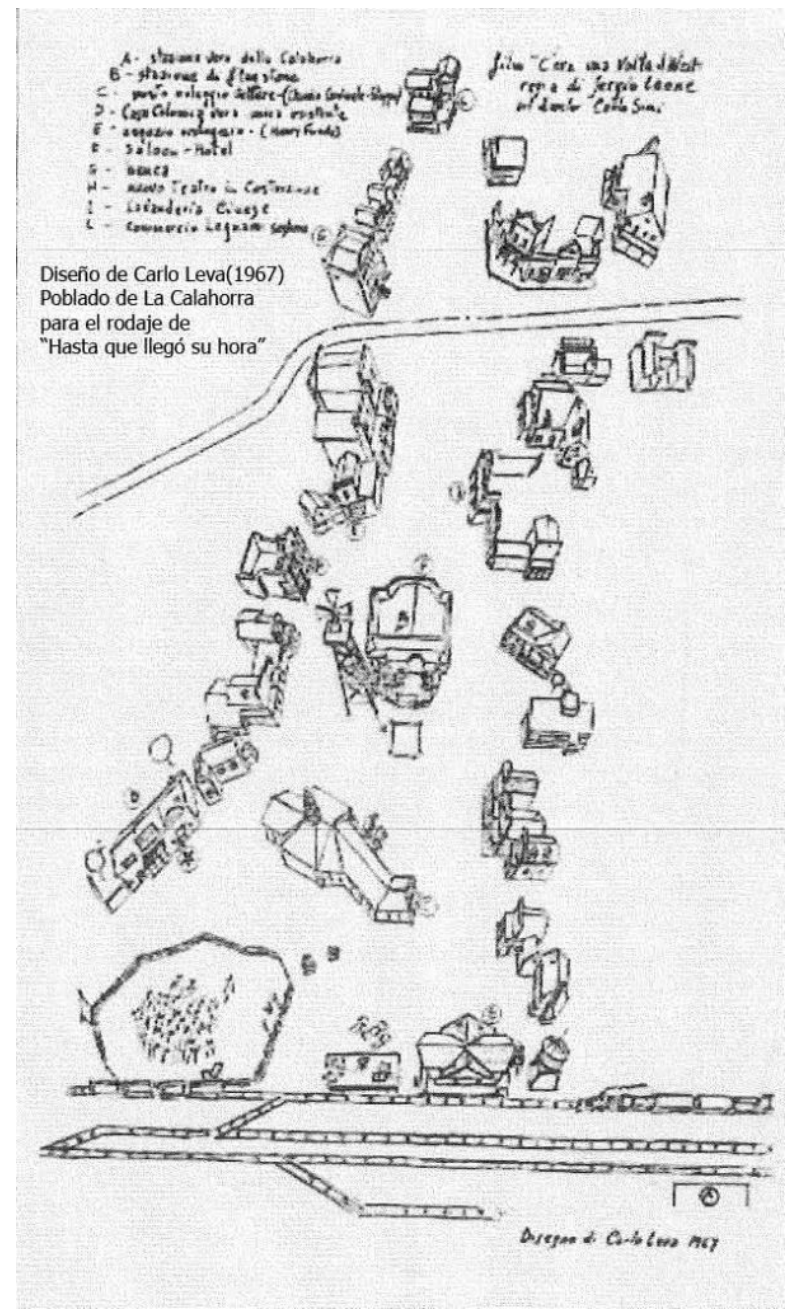

Figura 10. Poblado Leone, La Calahorra. (Ventajas y Sánchez, 2003). https://rinconesdegranada.com/guadix-de-cine

Igualmente señalar a actores, hoy día consagrados, que tuvieron sus primeros escarceos con la industria del cine en este territorio como Omar Sharif, Geraldine Chaplin, Claudia Cardinale, Henry Fonda, Charles Bronson, Clint Eastwood,
Lee Van Cleef, Bud Spencer, Harrison Ford, Sean Connery, James Coburn, Alain Delon, Ursula Andress, Terence Hill, Orson Welles, Raquel Welch, Burt Reynolds, Sancho Gracia, Fernando Rey, Richard Widmark, Franco Nero, Yul Brynner y un largo elenco de grandes actores y actrices, músicos y artistas. Otro aspecto importante a destacar, es la presencia en Guadix a lo largo de estos años de directores, productores y músicos cinéfilos de proyección internacional; muchos de ellos han llegado al culmen de sus carreras con la consecución de los más ansiados premios en el mundo del cine.

Por todo lo expuesto este proyecto se plantea como el inicio de una investigación más amplia que nos permita seguir en la profundización y búsqueda de esos clichés y de su origen en la creación cultural. El cine es una herramienta de gran utilidad en cualquier contexto investigador o didáctico. Teniendo en cuenta estas bases conceptuales, el análisis realizado ha seleccionado diferentes categorías y criterios que van desde la temática hasta una profundización textual y narrativa, finalizando en una reflexión en torno al modelo de sociedad que representan estas películas de la época que podrían sumarse en el futuro a esta línea de análisis. El inmenso valor de los muchos y variados rodajes como documentos: Por lo tanto, tenemos un amplísimo trabajo por seguir investigando, seguir en la profundización y búsqueda de esos clichés y de su origen en la creación cultural, el cine es una herramienta de gran utilidad en cualquier contexto investigador o didáctico.

\section{CONCLUSIONES Y PRINCIPALES LINNEAS DIDÁCTICAS}

La principal conclusión, vinculada al objetivo principal de este estudio, es la combinación del paisaje, telón de fondo de los rodajes, imprescindible para un resultado sorprendente. Hemos de entender que puede ser manipulado y con- 
vertido en un estereotipo deformante, acorde con la representación irrealista del director y su equipo, o puede ser aceptado como "protagonista", que identifique el territorio en una obra fílmica, y el resultado para ser estudiada. Por ello, es importante impulsar el visionado crítico que unido a la contextualización de la época, fomente la comprensión del legado patrimonial y de la historia, pero también la capacidad para disfrutar y encontrar sentido a los recursos propios del lenguaje audiovisual y cinematográfico, integrando la Didáctica de las Ciencias Sociales con la Educación Patrimonial y Mediática. En concreto, se ha podido comprobar cómo el diseño de personajes, acciones y lugares confirma esos prototipos sociales que, en España, fueron firmemente construidos y consolidados, especialmente a través del cine y de la representación del turismo.

Por otra parte, en relación con el segundo objetivo: investigar, conocer y difundir, tanta variedad de rodajes se presta a poner nuestra atención especial en el estudio los aspectos técnicos y discursivos, al tener tantos en una zona geográfica no muy grande, y con tanta variedad de tipos de largometrajes, y algunos poco habituales, hace complicado enmarcar, y que se actualizan año a año, incluida las producciones para televisión e internet. Un trabajo que merece ser destacado es el realizado por Orson Welles, que dirigió su mirada en el recorrido antropológico y visual por el paisaje de las cuevas de Guadix con Quijote, película que dejó sin poder terminar, rodada en blanco y negro: https://youe tu.be/VJEOO_xyPgc.

La zona tiene una luz magnifica, al igual se presta a un escenario intemporal, que puede destacar cualquier tiempo y época cultural, igualmente apoyándose en la técnica de representación del color, lo que favorece la imagen de una Accitania deslumbrante en todos sus contrastes. Esa "realidad, que se estaba construyendo como arquetipo, incluye no solo imágenes tradicionales en el cine de ficción, teatrales, incluso se han realizado rodajes con «naves espaciales». Podemos encontrarnos con tomas documentales que no disimulan su carácter testimonial.

En resumen el caso analizado, fuerza todo tipo de estereotipos incluso ensimismarse, es pues patrimonio fílmico y por tanto arte de la memoria y la identidad. Testimonio del contraste entre una sociedad que comenzaba a desarrollarse tras un periodo difícil de posguerra en España y Europa. Recordar el rodaje de "La piel quemada" de Josep María Forn: https://youtu.be/FntlnO3ljzs

Además, el contexto histórico, en el que las relaciones entre Estados Unidos y España habían mejorado, hace comprender la razón de protagonizar como destino una producción norteamericana, que además aportaba Paisajes y Paisanaje, estos apreciados y muy adecuados, que además cobraban muy barato, se disponía de técnicos y personal de apoyo para todo tipo de rodajes que les favorecía ventajosamente al no tener que desplazar este personal desde $\mathrm{Ma}-$ drid, etc. Centrándonos en "la acción educativa» con materiales audiovisuales este trabajo se integra en un modelo de aproximación y pedagógica interdisciplinar, siendo recomendable el estímulo para centrar el análisis crítico, basado en el descubrimiento del potencial de aprendizaje que constituye en sí una película de la segunda mitad del siglo XX. Anteriormente hemos recomendado acciones y recomendaciones para trabajar de modo interdisciplinar y «Aprender a Aprender». Por ejemplo una acción recomendada es identificar rasgos estéticos y discursivos, y dominar el lenguaje fílmico. Además, junto a la comprensión del mismo puede estimularse la propia acción creativa, basada en la creación de guion, planificación y preparación de rodaje, recreación de una secuencia concreta en la que se muestre el patrimonio más próximo. Con salidas fuera del centro, "las aulas sin cuatro paredes", junto al debate cinematográfico es importante estimular la forma de seleccionar una 


\section{ANÁLISIS DEL PAISAJE CULTURAL DE GUADIX Y COMARCA A TRAVÉS DEL CINE Manuel CORTÉS-MAGÁN}

película de las rodadas en la Accitania, y comenzar una reflexión sobre esa época y la realidad que muestre la película seleccionada. Acabando con la difusión de todo el proceso, montaje y edición de su trabajo.

\section{REFERENCIAS}

Aguilera, C. (2015). Jack Cardiff: una leyenda centenaria. Dirigido por, (452), 74-75.

Aparici, R. y García Matilla, A. (2008). Lectura de imágenes en la era digital. Ediciones de la Torre.

Bardin, L. (1986). Análisis de contenido (C. Suárez, trad.). Akal.

Banacolocha, J. y Bas, J. (Productores); Olivares, J. (Creador); Frades, J. (Director) (20122014). Isabel [Serie de TV]. España: Diagonal TV y TVE.

Banalocha, J.; Romero, N. (Productores); Ferrer, O. (Director) (2015- 2016). Carlos, Rey Emperador [Serie de TV]. España: Diagonal TV y TVE.

Bordwell, D. (1996). La narración en el cine de ficción (P. Vázquez Mota, trad.). Paidós.

Cambil, M.E. y Fernández , A.R. (2017). El concepto actual de Patrimonio Cultural y su valor educativo: fundamentación teórica y aplicación didáctica. En M.E. Cambil y Tudela, A.( Coords). Educación y patrimonio cultural. Fundamentos, contextos y estrategias didácticas (pp. 27-46). Madrid: Pirámide.

Canet, F. y Prósper, F. Narrativa audiovisual. Estrategias y recursos. Síntesis.

Caparros, M. D., Fernandez, I. y Soler, J. (1997). La producción cinematográfica en Almería: 1951-1975. Instituto de Estudios Almerienses.

Carrasco, J. J. (2012). Granada y el Cine: Almuzara.

Carmona, R. (2003). Cómo se comenta un texto fílmico. Cátedra.

Chatman, S. (1990). Historia y discurso. La estructura narrativa en la novela y en el cine. (M.J. Fernández Prieto, trad.).Taurus.
Gaberscek, C. (2077). II vicino west. Sette location del cinema western in Spagna. Ribis

Gómez Tarín, F.J. (2011). Elementos de narrativa audiovisual: Expresión y narración. Shangrila.

Hernández Hernández, F. (2007). Espigador@s de la Cultura Visual. Octaedro.

Krippendorff, Klaus. (1990). Metodología de análisis de contenido. Teoría y práctica (L. Wolfson, trad.). Paidós.

Marfil-Carmona, R. (2018). Historia de España y series de televisión. Posibilidades didácticas de 'Isabel', 'Carlos, Rey Emperador' y 'El Ministerio del Tiempo'. En R. Marfil-Carmona, S. Osuna-Acedo y P. González-Aldea (eds.), Innovación y esfuerzo investigador en la Educación Mediática contemporánea (pp. 275-292). Egregius y Grupo de Investigación GICID de la Universidad de Zaragoza. http://hdl.handle.net/10481/51362

Moya, J. M. (2011). Cabalgando hacia la aventura. Almería y la industria del cine. Círculo Rojo. https://editorialcirculorojo.com/cabalt gando-hacia- la-aventura-almeria-y-la-industria-del-cine-2/

Mirzoeff, N. (2016). Cómo ver el mundo. Una nueva introducción a la cultura visual ( $P$. Hermida Lazcano, trad.). Paidós.

Moreno, I. (1999). El patrimonio cultural como capital simbólico: valoración y usos. En Anuario etnológico de Andalucía 19951997 (pp. 325-330). Junta de Andalucía.

Mulvey, L. (1988). Placer visual y cine narrativo. Documentos de trabajo. Fundación Instituto Shakespeare/Instituto de cine y RTV. Episteme.

Prats, C. y Mayol, M. (2001). Sergio Leone: Cinema, Cinema (TV). https://www.filmaffinity. com/es/film893094.html

Pérez Siquier, C. (2005). Almería y el cine. Instituto de Estudios Almerienses.

Prósper Ribes, J. (2004). Elementos constitutivos del relato cinematográfico. Universidad Politécnica de Valencia. 


\section{ANÁLISIS DEL PAISAJE CULTURAL DE GUADIX Y COMARCA A TRAVÉS DEL CINE Manuel CORTÉS-MAGÁN}

Simi, C. L' Amérique de Sergio Leone (1998). Festival internacional cinéma Médirerrané de Montpellier.

Schmidt Noguera, M. (2008). Análisis de la realización cinematográfica. Síntesis.

Terré, L. (2006). Historia del grupo fotográfico AFAL. Photovision.

Ventajas, F. y Sánchez M. A. ( 2003). Guadix y el cine. Historia de los rodajes cinematográficos en la comarca accitana (1924-2002). Asociación para el desarrollo rural de la comarca de Guadix.

Walker, J. y Chaplin, S (2002). Una introducción a la cultura. 